\title{
Effects of salbutamol aerosol combined with magnesium sulfate on T-lymphocyte subgroup and Th1/Th2 cytokines of pediatric asthma
}

\author{
MIN DIAO, JIE MIN, FEI GUO and CHONG-LIN ZHANG \\ Department of Respiratory Medicine, Xuzhou Children's Hospital, Xuzhou, Jiangsu 221002, P.R. China
}

Received July 19, 2016; Accepted November 9, 2016

DOI: $10.3892 /$ etm.2016.3912

\begin{abstract}
The aim of the study was to analyze the effects of the intravenous infusion of salbutamol aerosol combined with magnesium sulfate in the treatment of pediatric asthma and the subsequent effects on the levels of T-lymphocyte subgroups and Th1/Th2 cytokines. A total of 86 patients with pediatric asthma, first diagnosed and treated at the Xuzhou Children's Hospital, were continuously selected and randomly divided into an observation group of 44 cases and control group of 42 cases. The patients in the control group were treated with budesonide atomization inhalation, while the children in the observation group were treated with intravenous infusion of salbutamol aerosol combined with magnesium sulfate. The therapeutic effects in the groups were compared. After treatment, the levels of serum $\mathrm{CD}^{+}$and $\mathrm{CD}^{+}$decreased when compared to before treatment; the levels of $\mathrm{CD}^{+}$and $\mathrm{CD} 4^{+} / \mathrm{CD} 8^{+}$also increased, but the observation group had more significant improvement. Differences were statistically significant $(\mathrm{P}<0.05)$. After treatment, the levels of serum interleukin-2 (IL-2) and interferon- $\gamma(\mathrm{IFN}-\gamma)$ increased when compared to before, while levels of IL- 4 and IL- 6 decreased, and the observation group had more significant improvement. The differences were statistically significant $(\mathrm{P}<0.05)$. After treatment, the levels of VT, t-PTEF/t-E, MTIF/MTEF and TEF75/PTEF increased when compared to before; the observation group had more significant improvement. The differences were statistically significant $(\mathrm{P}<0.05)$. The effective rate and degree of treatment for the observation group were significantly higher than those of the control group and differences were statistically significant $(\mathrm{P}<0.05)$. The intravenous infusion of salbutamol aerosol combined with magnesium sulfate in the treatment of pediatric asthma can significantly improve therapeutic effects and lung functions, improve immune functions and relieve
\end{abstract}

Correspondence to: Dr Chong-Lin Zhang, Department of Respiratory Medicine, Xuzhou Children's Hospital, 18 Sudibei Road, Xuzhou, Jiangsu 221002, P.R. China

E-mail: zhangchonglin3611@163.com

Key words: salbutamol aerosol, magnesium sulfate, pediatric asthma, T lymphocyte subgroup, Th1/Th2 cytokines inflammatory reactions. Therefore, it indicates better clinical application and promotion value.

\section{Introduction}

Bronchial asthma in children is a chronic inflammatory disease characterized by bronchial hyper-responsiveness and mediated by various cells, including mast cells, T lymphocytes and eosinophilic granulocytes (1). The main clinical symptoms included chest distress, annihilation and coughing caused by airway constriction, which can easily induce weakness of breathing, cyanosis and depression signs (2). Due to imperfect immune functions and the increase in environmental pollution, the morbidity rate of bronchial asthma in children has increased gradually, accounting for $10-30 \%$ of preschool children (3). This condition occurs frequently.

Although aerosol inhalation of hormone or theophylline drug has significant effects on anti-inflammation and relieves airway spasm, too much hormone can cause adverse reactions, including hypokalemia and osteoporosis (4). It also affects normal growth and development and the intellectual growth of children (4). As a selective $\beta_{2}$ receptor stimulant, salbutamol has the functions of relaxing airway smooth muscle and inhibiting the release of basophilic granulocytes, mast cells and their media, and therefore, can effectively relieve airway spasms (5). Magnesium sulfate has the function of relieving airway spasm and eliminating non-specific inflammation (6).

The present study aimed to analyze the effects of salbutamol aerosol combined with magnesium sulfate in the treatment of pediatric asthma and provide a reference for a reasonable selection of therapeutic protocol.

\section{Materials and methods}

General data. A total of 86 cases of pediatric asthma, first diagnosed and treated at the Xuzhou Children's Hospital (Jiangsu, China) from January 2013 to January 2016, were continuously selected. Inclusion criteria for the study were: i) Diagnosis of asthma according to the Diagnostic Criteria for Bronchial Asthma put forward by Chinese Medical Association; ii) age ranging from 2 to 14 years; iii) at onset, children had the symptoms of chest distress, cough, cyanotic lips and buzzing in the lungs; and iv) parents had signed informed consent form. Exclusion criteria for the study were: i) Utilization of 
hormone drugs within the preceding 30 days; ii) non-simple asthma, such as onset of pneumonia asthma, cough asthma and exercise-induced asthma; and iii) children with abnormal growth and development, such as congenital diseases, hereditary metabolic diseases and autoimmune disease.

Subjects were divided into an observation group of 44 cases and control group of 42 cases by applying a random number method. The observation group included 25 cases of males and 19 cases of females, with the age ranging between 1.5 and 13.5 years and averaged at $6.4 \pm 3.6$ years. The course of asthma was between 3 days to 3 months, with the median time of 15.7 days. The control group included 27 cases of males and 15 cases of females, with the age ranging between 2.0 and 12.5 years and averaged at $6.6 \pm 3.4$ years. The course of asthma was 5 days to 3.5 months, with the median time of 16.8 days. The baseline information of the two groups had comparability.

Research methods. Children in the control group were administered the therapeutic protocol of budesonide aerosol. Different drug dosages were administered according to divisions of age. For children aged $<7$ years, drugs were administered once every morning and evening, respectively, with each dose of $100 \mu \mathrm{g}$. In severe cases, drugs were administered once every 6 h, 4 times a day, with each dose of $100 \mu \mathrm{g}$. For children aged $>7$ years, drugs were administered once every morning and evening, respectively, with each dose of $200 \mu \mathrm{g}$. In severe cases, drugs were administered once every $6 \mathrm{~h}$, with each dose of $200 \mu \mathrm{g}, 4$ times a day. The present study was approved by the ethics committee of Xuzhou Children's Hospital. Signed written informed consent was obtained from the parents of the participants prior the study.

Children in the observation group were administered the therapeutic protocol of intravenous infusion of salbutamol aerosol combined with magnesium sulfate. For children aged $<7$ years, $100 \mu \mathrm{g}$ salbutamol aerosol was inhaled each time. In case of severe asthma, $200 \mu \mathrm{g}$ was inhaled each time, twice every morning and evening. For children aged $>7$ years, $200 \mu \mathrm{g}$ was inhaled each time, once every morning and evening, respectively. In severe cases, the drug was used every $6 \mathrm{~h}$, with $200 \mu \mathrm{g}$ dosage each time. During the period of treatment, children aged $<7$ years were treated by a slow intravenous infusion of $2.5 \%$ magnesium sulfate solution, which was prepared by dissolving $10 \mathrm{ml}$ of $10 \%$ magnesium sulfate into a $5 \%$ glucose injection. Children aged $>7$ years were treated by an intravenous infusion of $10 \%$ magnesium sulfate, which was prepared by dissolving $15 \mathrm{ml}$ of $25 \%$ magnesium sulfate in $10 \%$ glucose injection. For the children of both groups, 7 days was the total course of treatment. During the period of treatment, the vital signs were closely monitored.

Observation index and evaluation method. The levels of $\mathrm{CD}^{+}, \mathrm{CD}^{+}, \mathrm{CD}^{+}$and $\mathrm{CD} 4^{+} / \mathrm{CD}^{+}$of the T-lymphocyte subgroups and the levels of interleukin-2 (IL-2), IL-4, IL-6 and interferon- $\gamma(\mathrm{IFN}-\gamma)$ before and after treatment were compared. Blood (3-5 ml) was collected from the peripheral vein, under the condition of empty stomach, and was centrifuged at 4,000 x $\mathrm{g}$ for $5 \mathrm{~min}$. The upper serum was placed into an EP tube and frozen at $-20^{\circ} \mathrm{C}$ for use. The contents of the T-lymphocyte subgroup were tested using a sorting flow cytometer (Beckman Coulter, Inc., Brea, CA, USA). The level of cytokines was tested by the ELISA method. The kit was purchased from Sigma-Aldrich (St. Louis, MO, USA) and the microplate reader was purchased from Beijing Liuyi Instrument Factory (Beijing, China). The evaluation steps were carried out according to the kit instructions.

Changes in the indexes of lung functions before and after treatment were compared. Special lung function monitor for children (Applied Biosystems, Foster City, CA, USA) was applied to determine peak tidal expiratory flow-volume loop, including tidal volume (VT), ratio of time to peak [t-PTEF/t-E (\%)], ratio of momentary flow rate in case of exhalation of $75 \%$ of tidal volume to peak tidal expiratory flow [TEF75/PTEF (\%)] and ratio of medium term inspiration flow to medium term expiration flow (MTIF/MTEF).

The effective rates of treatment were compared. The criteria of judgment of therapeutic effects included: i) Recovery, clinical symptoms and signs disappeared, the indexes of lung functions returned to normal, and no recurrence appeared within 1 month; ii) remarkable effect, clinical symptoms and signs had almost disappeared and the times of need for aerosol inhalation within 1 month were $<2$ times; iii) effective, clinical symptoms and signs relieved significantly and the times of need for aerosol inhalation within 1 month were $<10$ times; and iv) no effect, clinical symptoms and signs had no obvious improvement, lung functions had no obvious improvement, and aerosol inhalation was not sensitive.

Statistical analysis. Statistical analysis was conducted by the SPSS 20.0 statistical software (SPSS, Inc., Chicago, IL, USA). Quantitative data are demonstrated by mean \pm standard deviation. Inter-group comparison was performed using an independent sample t-test. Intra-group comparison was performed using a paired t-test. Enumeration data were indicated by cases or (\%). Inter-group comparison was performed using a $\chi^{2}$ test. Comparison of ranked data was performed using a non-parametric rank-sum test. $\mathrm{P}<0.05$ was considered to indicate a statistically significant difference.

\section{Results}

Comparison of the level of serum T-lymphocyte subgroup before and after treatment. Before treatment, the levels of serum $\mathrm{CD}^{+}, \mathrm{CD}^{+}, \mathrm{CD}^{+}$and $\mathrm{CD}^{+} / \mathrm{CD}^{+}$of the two groups were compared; the difference was of no statistical significance $(\mathrm{P}>0.05)$. After treatment, the levels of serum $\mathrm{CD}^{+}$ and $\mathrm{CD} 8^{+}$decreased compared to before treatment and the difference was statistically significant $(\mathrm{P}<0.05)$ (Table I).

Comparison of the level of serum cytokines before and after treatment. Before treatment, the levels of serum IL-2, IL-4, IL- 6 and IFN- $\gamma$ were compared and the differences were not statistically significant $(\mathrm{P}>0.05)$. After treatment, the levels of serum IL-2 and IFN- $\gamma$ increased when compared to before treatment, levels of IL-4 and IL- 6 decreased, and the observation group had a significant improvement. The differences were statistically significant $(\mathrm{P}<0.05)$ (Table II).

Comparison of lung function indexes before and after treatment. Before treatment, the levels of VT, t-PTEF/t-E, MTIF/MTEF and TEF75/PTEF of the groups were compared 
Table I. Comparison of the level of serum T lymphocyte subgroup before and after treatment (\%).

\begin{tabular}{|c|c|c|c|c|c|c|c|c|}
\hline \multirow[b]{2}{*}{ Groups } & \multicolumn{2}{|c|}{$\mathrm{CD}^{+}$} & \multicolumn{2}{|c|}{$\mathrm{CD}^{+}$} & \multicolumn{2}{|c|}{$\mathrm{CD}^{+}$} & \multicolumn{2}{|c|}{$\mathrm{CD}^{+} / \mathrm{CD}^{+}$} \\
\hline & $\begin{array}{c}\text { Before } \\
\text { treatment }\end{array}$ & $\begin{array}{c}\text { After } \\
\text { treatment }\end{array}$ & $\begin{array}{c}\text { Before } \\
\text { treatment }\end{array}$ & $\begin{array}{c}\text { After } \\
\text { treatment }\end{array}$ & $\begin{array}{c}\text { Before } \\
\text { treatment }\end{array}$ & $\begin{array}{c}\text { After } \\
\text { treatment }\end{array}$ & $\begin{array}{c}\text { Before } \\
\text { treatment }\end{array}$ & $\begin{array}{c}\text { After } \\
\text { treatment }\end{array}$ \\
\hline Observation & $42.6 \pm 5.7$ & $32.4 \pm 4.3$ & $21.6 \pm 3.8$ & $26.7 \pm 3.2$ & $22.5 \pm 4.2$ & $16.7 \pm 3.5$ & $0.9 \pm 0.2$ & $1.6 \pm 0.3$ \\
\hline Control & $40.5 \pm 6.0$ & $35.6 \pm 4.4$ & $22.2 \pm 3.9$ & $24.3 \pm 3.3$ & $21.7 \pm 4.3$ & $18.3 \pm 3.6$ & $1.0 \pm 0.3$ & $1.3 \pm 0.4$ \\
\hline t-test & 0.123 & 3.639 & 0.152 & 3.957 & 0.163 & 4.521 & 0.201 & 4.321 \\
\hline P-value & 0.967 & 0.037 & 0.923 & 0.034 & 0.867 & 0.030 & 0.824 & 0.032 \\
\hline
\end{tabular}

Table II. Comparison of the level of serum cytokines before and after treatment $(\mu \mathrm{mol} / \mathrm{l})$.

\begin{tabular}{|c|c|c|c|c|c|c|c|c|}
\hline \multirow[b]{2}{*}{ Groups } & \multicolumn{2}{|c|}{ IL-2 } & \multicolumn{2}{|c|}{ IL-4 } & \multicolumn{2}{|c|}{ IL-6 } & \multicolumn{2}{|c|}{ IFN- $\gamma$} \\
\hline & $\begin{array}{c}\text { Before } \\
\text { treatment }\end{array}$ & $\begin{array}{c}\text { After } \\
\text { treatment }\end{array}$ & $\begin{array}{l}\text { Before } \\
\text { treatment }\end{array}$ & $\begin{array}{c}\text { After } \\
\text { treatment }\end{array}$ & $\begin{array}{l}\text { Before } \\
\text { treatment }\end{array}$ & $\begin{array}{c}\text { After } \\
\text { treatment }\end{array}$ & $\begin{array}{l}\text { Before } \\
\text { treatment }\end{array}$ & $\begin{array}{c}\text { After } \\
\text { treatment }\end{array}$ \\
\hline Observation & $35.6 \pm 7.2$ & $54.8 \pm 6.9$ & $32.7 \pm 5.6$ & $16.9 \pm 3.7$ & $24.5 \pm 3.6$ & $15.8 \pm 3.2$ & $16.5 \pm 4.3$ & $21.3 \pm 5.2$ \\
\hline Control & $37.5 \pm 7.5$ & $46.3 \pm 7.0$ & $31.8 \pm 5.5$ & $25.5 \pm 3.9$ & $23.2 \pm 3.5$ & $17.9 \pm 3.4$ & $17.2 \pm 4.5$ & $19.6 \pm 4.8$ \\
\hline t-test & 0.263 & 3.754 & 0.246 & 4.203 & 0.221 & 4.316 & 0.320 & 4.285 \\
\hline P-value & 0.857 & 0.035 & 0.862 & 0.030 & 0.896 & 0.028 & 0.763 & 0.030 \\
\hline
\end{tabular}

IL, interleukin; INF, interferon.

Table III. Comparison of lung function indexes before and after treatment.

\begin{tabular}{|c|c|c|c|c|c|c|c|c|}
\hline \multirow[b]{2}{*}{ Groups } & \multicolumn{2}{|c|}{$\mathrm{VT} / \mathrm{kg}(\mathrm{ml} / \mathrm{kg})$} & \multicolumn{2}{|c|}{ t-PTEF/t-E (\%) } & \multicolumn{2}{|c|}{ MTIF/MTEF } & \multicolumn{2}{|c|}{ TEF75/PTEF (\%) } \\
\hline & $\begin{array}{c}\text { Before } \\
\text { treatment }\end{array}$ & $\begin{array}{c}\text { After } \\
\text { treatment }\end{array}$ & $\begin{array}{c}\text { Before } \\
\text { treatment }\end{array}$ & $\begin{array}{c}\text { After } \\
\text { treatment }\end{array}$ & $\begin{array}{c}\text { Before } \\
\text { treatment }\end{array}$ & $\begin{array}{c}\text { After } \\
\text { treatment }\end{array}$ & $\begin{array}{c}\text { Before } \\
\text { treatment }\end{array}$ & $\begin{array}{c}\text { After } \\
\text { treatment }\end{array}$ \\
\hline Observation & $8.2 \pm 1.3$ & $10.5 \pm 1.6$ & $36.4 \pm 6.3$ & $45.7 \pm 6.6$ & $0.8 \pm 0.2$ & $1.3 \pm 0.4$ & $56.9 \pm 7.6$ & $68.5 \pm 8.0$ \\
\hline Control & $8.3 \pm 1.4$ & $9.2 \pm 1.7$ & $37.2 \pm 6.5$ & $42.3 \pm 6.7$ & $0.9 \pm 0.3$ & $1.0 \pm 0.4$ & $57.8 \pm 7.4$ & $62.3 \pm 8.2$ \\
\hline t-test & 0.326 & 3.864 & 0.345 & 4.326 & 0.332 & 4.128 & 0.376 & 4.649 \\
\hline P-value & 0.649 & 0.033 & 0.603 & 0.028 & 0.653 & 0.030 & 0.597 & 0.023 \\
\hline
\end{tabular}

Table IV. Comparison of effective rates of treatment (cases, \%).

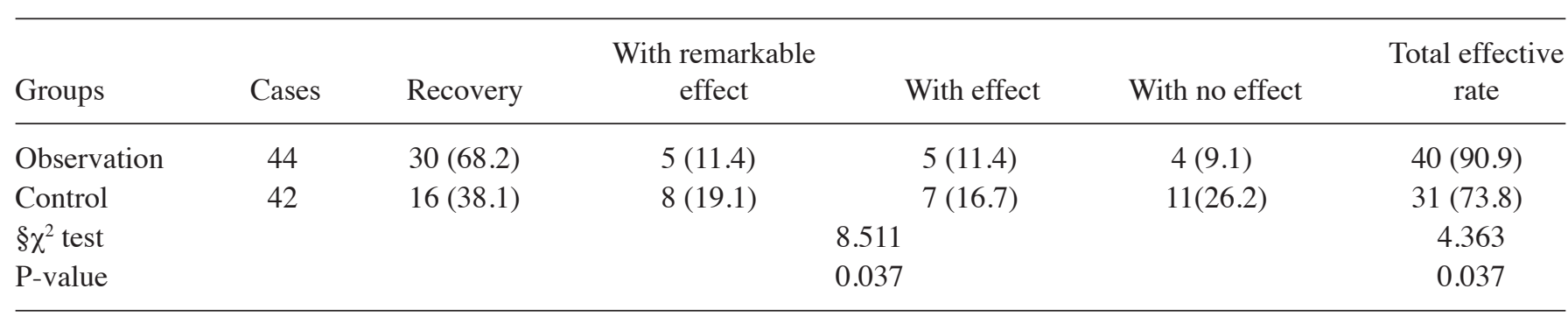

and the differences were not statistically significant $(\mathrm{P}>0.05)$. After treatment, the levels of the above indexes of both groups increased when compared to before and the observation group had more significant improvement. The differences were statistically significant $(\mathrm{P}<0.05)$ (Table III).
Comparison of effective rates of treatment. The effective rate and the degree of treatment of the observation group were significantly higher than those of the control group and the differences identified were statistically significant $(\mathrm{P}<0.05)$ (Table IV). 


\section{Discussion}

The pathogenesis of pediatric asthma is closely related to immune dysfunction and the level of inflammatory reaction carried out by our immune cells. An animal model proved that abnormal content of airway tissues, T-lymphocyte subgroups and the levels of Th1/Th2 cytokines played an important role in the occurrence of bronchial asthma, and severity of patient's condition and subsequent therapeutic effects (7). The cytokines released by the T-lymphocyte subgroups play an important role in the inflammatory reactions of the respiratory mucosa and mycoplasma pneumonia. In particular, the occurrence of pediatric asthma is most likely directly related to the Th1/Th2 balance disturbance with decreased Th1 and increased Th2 (8). The main function of Th1 cells is to secrete IL- 2 and IFN- $\gamma$, which can induce the activation of macrophages and generate immunoglobulin, mainly characterized by cytotoxic effects (9). The main function of Th 2 cells is to secrete IL-4 and IL-6, which can induce activation and secretion of macrophages and mast cells, which are mainly characterized by delayed type hypersensitivity (10). Salbutamol aerosol combined with magnesium sulfate can inhibit levels of relevant factors by significantly decreasing the levels of IL-4 and IL-6, increasing levels of IL-2 and IFN- $\gamma$, relieving bronchial hyperresponsiveness and inflammatory cascade reactions, and regulating the Th1/Th2 balance.

As a selective $\beta_{2}$ receptor stimulant, salbutamol has the function of relaxing bronchial smooth muscles, lowering permeability of peritubular capillaries and relieving bronchial spasms (11). Magnesium ions of magnesium sulfate can inhibit the release of acetylcholine to relax bronchial smooth muscles, relieve non-specific inflammation and can cause sedation and anti-spasm (12). Magnesium sulfate combined with salbutamol can reduce the sensitivity of eosinophilic granulocytes. Combined with a cysteine receptor, it can inhibit the activity of leukotrienes and effectively inhibit the progress of airway inflammation (13).

This study showed that levels of serum $\mathrm{CD}^{+}$and $\mathrm{CD} 8^{+}$ of the observation group decreased significantly more than those of the control group. The levels of $\mathrm{CD}^{+}$and $\mathrm{CD} 4^{+} / \mathrm{CD}^{+}$ increased as well. The levels of serum IL- 2 and IFN- $\gamma$ increased more in the observation group than in the control group. The levels of IL-4 and IL- 6 decreased in the observation group. The levels of VT, t-PTEF/t-E, MTIF/MTEF and TEF75/PTEF increased more in the observation group than in the control group. The effective rate and effective degree of treatment were significantly higher in the observation group. The differences were statistically significant. All of these results indicate that the intravenous infusion of salbutamol aerosol combined with magnesium sulfate in the treatment of pediatric asthma could significantly improve therapeutic effects and lung functions, improve immune functions and relieve inflammatory reactions. Therefore, this drug can have better application and promotion value. The shortcomings of this study lie in that no in-depth analysis was conducted regarding the cell signaling pathway that plays a role in the treatment of pediatric asthma by salbutamol aerosol combined with magnesium sulfate. Further analysis is needed for the mechanism of intervention by the levels of $\mathrm{T}$ lymphocyte subgroup and the levels of Th1/Th2 cytokines, which provide evidence for the theoretical studies on the occurrence of asthma.

\section{References}

1. Gao SJ, Ge YP and Zhang CJ: Correlation between fractional exhaled nitric oxide levels and efficacy of inhaled corticosteroids in children with bronchial asthma. Am J Ther: Mar 17, 2016 (Epub ahead of print).

2. Chen B, Feng S and Yin XW: Clinical characteristics of different ages of children with acute exacerbation of bronchial asthma. Zhongguo Dang Dai Er Ke Za Zhi 18: 320-323, 2016 (In Chinese).

3. Nakamura T, Hashizume M, Ueda K, Shimizu A, Takeuchi A, Kubo T, Hashimoto K, Moriuchi H, Odajima H, Kitajima T, et al: Asian dust and pediatric emergency department visits due to bronchial asthma and respiratory diseases in Nagasaki, Japan. J Epidemiol: May 14, 2016 (Epub ahead of print).

4. Hong $J$ and Bao Y: Emphasis on standardized diagnosis and treatment of bronchial asthma in children. Zhonghua Er Ke Za Zhi 54: 161-162, 2016 (In Chinese).

5. Bandaru S, Alvala M, Akka J, Sagurthi SR, Nayarisseri A, Singh SK and Mundluru HP: Identification of small molecule as a high affinity $\beta_{2}$ agonist irrespectively targeting wild and mutated (Thr164Ile) $\beta_{2}$ adrenergic receptor in the treatment of bronchial asthma. Curr Pharm Des: May 13, 2016 (Epub ahead of print).

6. Albuali WH: The use of intravenous and inhaled magnesium sulphate in management of children with bronchial asthma. J Matern Fetal Neonatal Med 27: 1809-1815, 2014.

7. Han RF, Li HY, Wang JW and Cong XJ: Study on clinical effect and immunologic mechanism of infants capillary bronchitis secondary bronchial asthma treated with bacterial lysates Broncho-Vaxom. Eur Rev Med Pharmacol Sci 20: 2151-2155, 2016.

8. Rogala B, Bozek A, Gluck J and Jarzab J: Prevalence of IgE-mediated allergy and evaluation of Th1/Th2 cytokine profiles in patients with severe bronchial asthma. Postepy Dermatol Alergol 32: 274-280, 2015.

9. Al-Daghri NM, Alokail MS, Draz HM, Abd-Alrahman SH, Yakout SM and Clerici M: Th1/Th2 cytokine pattern in Arab children with severe asthma. Int J Clin Exp Med 7: 2286-2291, 2014.

10. Yamada Y, Matsumoto K, Hashimoto N, Saikusa M, Homma T, Yoshihara S and Saito H: Effect of Th1/Th2 cytokine pretreatment on RSV-induced gene expression in airway epithelial cells. Int Arch Allergy Immunol 154: 185-194, 2011.

11. Shah NJ, Vinod Kumar S, Gurusamy U, Annan Sudarsan AK and Shewade DG: Effect of ADRB2 (adrenergic receptor $\beta_{2}$ ) gene polymorphisms on the occurrence of asthma and on the response to nebulized salbutamol in South Indian patients with bronchial asthma. J Asthma 52: 755-762, 2015.

12. Grover S, Jindal A, Bansal A and Singhi SC: Acute bronchial asthma. Indian J Pediatr 78: 1388-1395, 2011.

13. Lajqi N, Ilazi A, Kastrati B and Islami H: Comparison of glucocorticoid (budesonide) and antileukotriene (montelukast) effect in patients with bronchial asthma determined with body plethysmography. Acta Inform Med 23: 347-351, 2015. 